\title{
Configuración de una ciudadanía comunicativa en Medellín, Colombia, 1990-2010
}

\author{
Elva Mónica García Bustamante \\ monica.garcia@ucp.edu.co \\ Universidad Católica de Pereira
}

Recibido: 31/7/2018 / Aceptado: 26/9/2018

doi: 10.26439/contratexto2018.n030.3153

\begin{abstract}
Resumen. Este artículo consigna resultados parciales de la investigación doctoral sobre las contribuciones que en materia de comunicación se dieron en Medellín en el marco de los procesos de formación ciudadana gestados por el tercer sector y entidades territoriales en pro de la promoción de escenarios de diálogo, participación y alternativas de vida para los habitantes de la ciudad. Las estrategias comunicacionales que se desarrollaron en este marco a partir de la década del noventa demarcaron nociones y metodologías del hacer comunicativo que fueron apropiadas por la comunidad para la intervención en sus barrios. Desde allí construyeron plataformas de interacción con otros actores sociales, configurando entramados vinculares que hoy podrían entenderse como el ejercicio de una ciudadanía comunicativa.
\end{abstract}

Palabras claves: comunicación / ciudadanía comunicativa / autoestima social / Medellín 


\title{
Configuration of a communicative citizenship in Medellín, Colombia, 1990-2010
}

\begin{abstract}
This article reports partial results of the doctoral research on communication-related contributions conducted in Medellin, in the context of citizen education processes developed by third-sector organizations and territorial entities, in favor of the promotion of dialogue scenarios, participation and life alternatives for the inhabitants of the city. The communication strategies developed in this framework from the nineties demarcated notions and communication methodologies that were appropriated by the community for the intervention in its neighborhoods. From that point, platforms for interaction with other social actors were built by means of forming bonds that today could be understood as the exercise of a communicative citizenship.

Keywords: communication / communicative citizenship / social self-esteem / Medellín
\end{abstract}




\section{Introducción}

$\mathrm{E}$ n Medellín ${ }^{1}$ se adelanta la discusión sobre la "Política pública de medios alternativos independientes, comunitarios y ciudadanos" (https://www.politicamediosmed.com), dirigida a fortalecer la democracia, incrementar la movilización social, proteger la identidad y la memoria de los medios, y robustecer las redes y una agenda común. En su formulación participan diecinueve organizaciones sociales de base, con el ánimo de fortalecer los procesos de comunicación en los barrios y corregimientos que configuran la ciudad.

En dicho escenario, situaron la discusión por el derecho a la libertad de expresión en la esfera pública y, por el perfil de los participantes (medios alternativos, independientes y organizaciones cívicas), posicionaron la comunicación como una dimensión del desarrollo social de la población. Hecho que no es menor, porque con ello se reconoce que, en la base, es decir, en los barrios, la población encontró en la acción comunicativa alternativas para procurar mejores condiciones de vida que trascienden los medios.
Varias de estas organizaciones llevan más de treinta años trabajando en los barrios y encontraron en la praxis comunicativa una forma de interactuar en la ciudad. Ellas apropian metodologías y estrategias de la educación popular y la comunicación para el desarrollo, lo que les define una forma de pensar y hacer la comunicación.

En la elaboración de la política se suma la Secretaría de Comunicaciones de la alcaldía, que actúa como coordinadora y garante. Esta dependencia se creó en el 2013, a raíz del giro que tuvo la concepción de la comunicación en el sector público en la primera década del presente siglo.

En términos de Mata (2006), dicha situación describe un escenario pleno del ejercicio de una ciudadanía comunicativa. La cuestión es esta: ¿cómo se configuró esto en la ciudad? ¿Qué hechos y circunstancias se dieron para que hoy haya una discusión acerca de los procesos de comunicación en la urbe y se construya un imaginario de ciudad desde estos actores?

Surge, entonces, el interés por hacer un estudio de las contribuciones que, en materia de comunicación, se dieron

1 Medellín es la segunda ciudad en importancia de Colombia. Es la capital del departamento de Antioquia, tiene una población aproximada de 2508452 habitantes según censo del Departamento Administrativo Nacional de Estadística (DANE) y está dividida en 16 comunas, 5 corregimientos y 275 barrios. 
en Medellín, lo que llevó a explorar los procesos de formación ciudadana que gestaron las organizaciones del tercer sector en interacción con la alcaldía².

En este sentido, el propósito de este artículo es dar a conocer resultados parciales de la investigación doctoral concluida Trayectos de la comunicación en procesos de formación de ciudadanía gestados entre entidades gubernamentales y organizaciones del tercer sector, Medellín (1990-2010). Entre sus objetivos, pre-tendió identificar concepciones, metodologías y estrategias desarrolladas como aportes a los hechos de transformación de la ciudad desde el campo de la comunicación.

Para el presente artículo se hará un encuadre sucinto del estudio, se profundizará en algunos acontecimientos que contextualicen la ciudad como escenario complejo de intrincadas relaciones políticas, sociales y culturales; se bosquejará el referente teórico sobre ciudadanía comunicativa, $\mathrm{y}$, por último, se tratará de sintetizar algunos legados que se encontraron.

\section{Acerca de la investigación}

La Constitución Política de 1991 habilitó el escenario para que las organizaciones no gubernamentales (en adelante, ONG) se visibilizaran en la esfera pública gracias a los procesos de formación ciudadana, cuya esencia se centraba en el fortalecimiento del tejido social, empoderamiento de herramientas de gestión y participación, y la promoción de una ética pública. Las acciones comunicativas se consideraban transversales a las dinámicas de intervención comunitaria, hubo creación de colectivos, medios alternativos y producción de contenidos orientados a la circulación de los discursos barriales en el ámbito urbano.

Las ONG conformaron equipos interdisciplinarios que actuaron como enlace entre las comunidades con actores estatales y la empresa privada. El interés de la investigación se centró en estudiar la gestión que impulsaron $\mathrm{y}$, en especial, el rol, las funciones y las concepciones que desempeñaron los comunicadores. La mirada, entonces, se focalizó en dos ONG. Una fue la Fundación Social, por su metodología de intervención, su capacidad económica - que le permitió la sostenibilidad de sus proyectos- y por los modelos de comunicación implementados. La otra fue la Corporación Región, cuya fortaleza está en la investigación de la ciudad, porque se desliga un poco de las posturas tradicionales del discurso de izquierda, y en ello fue pionera en la implementación de estrategias de comunicación que generaran opinión pública.

2 La Confederación Colombiana de ONG (CCONG) define las organizaciones constituidas por ciudadanos para producir bienes públicos, como lo son la justicia, la democracia, la paz, los derechos humanos, etcétera (Villar, 2010, p. 10). 
Apartándose de la producción de contenidos en medios alternativos, optó por espacios en comerciales y por entablar un diálogo social amplio que incluyera al Estado ${ }^{3}$.

La pregunta central del estudio fue esta: ¿qué contribuciones de comunicación se hicieron en la ciudad de Medellín a partir de los procesos de formación ciudadana gestados por Fundación Social y Corporación Región, en cooperación con entidades gubernamentales y otras organizaciones civiles entre 1990 y el 2010? Se partió de dos supuestos: primero, la comunicación como categoría teórica y práctica ha sido poco estudiada en los procesos de transformación de la ciudad. Segundo, el saber comunicacional generado por las organizaciones objeto se instaló en las entidades gubernamentales por medio del trabajo de cooperación y por la vinculación de los comunicadores que laboraron en las ONG y luego pasaron al sector público.

Entre el 2004 y el 2011, la ciudad fue gobernada por líderes procedentes del ámbito académico y del tercer sector, cuyo accionar se diferenciaban de las prácticas políticas tradicionales: Sergio Fajardo (2004-2007) y Alonso Salazar
(2007-211) ${ }^{4}$. Sus administraciones reconocieron el talento humano y el acumulado histórico existente, y conformaron equipos de trabajo con personas de igual procedencia, entre ellos, comunicadores, quienes aportaron la experiencia sobre estrategias de comunicación realizadas por las ONG en alianzas de cooperación internacional y con el mismo Estado.

El estudio se inscribió en el paradigma cualitativo, cuyo alcance es descriptivoexploratorio. $\mathrm{Su}$ propósito fue el de comprender un fenómeno a partir de las relaciones existentes entre sujetos, discursos y contextos concretos a lo largo de dos décadas; por ello, su análisis fue de tipo inductivo centrado en lo que enuncian los sujetos sociales. Se optó por el enfoque biográfico (Bertaux, 1999), el cual se comprende como la investigación cuyas fuentes proporcionan información de tipo personal para dar cuenta de una vida, un suceso o una situación social dados en un contexto y momento histórico determinado, al cual le dan sentido las dinámicas intersubjetivas que allí se tejen.

El anclaje histórico se demarcó por los proyectos de comunicación impulsados por las organizaciones objeto y por

3 En Colombia, algunas ONG se han caracterizado por poseer discursos de izquierda y estar en oposición a los grupos de poder. Corporación Región consideró que, frente a la necesidad de trabajar por la transformación de la ciudad, era necesaria la participación de todos los actores, de ahí su apertura al diálogo con el sector público. Su objetivo era incidir en la esfera pública y, para ello, los medios alternativos no eran la única vía. Esa es la razón de su apuesta por estar en los medios de comunicación locales y regionales, estatales y privados.

4 Salazar es periodista y fue socio fundador de Corporación Región. 
la relevancia que tuvieron en la ciudad, como el programa de televisión Arriba mi barrio (1990-1997), la serie de televisión Muchachos a lo bien (1995-1997) y los procesos de intervención de Picacho con Futuro (zona Noroccidental) y Constructores de Sueños en la comuna 13 (1990-2004).

La unidad de trabajo se centró en siete comunicadores sociales que fueron partícipes de estos proyectos y laboraron en el escenario de lo público durante las dos administraciones municipales citadas. Con ellos, se construyeron relatos de vida a través de entrevistas biográficas que abordaban dimensiones socioestructurales y sociosimbólicas de las fuentes. Los cuestionarios fueron diferentes, acordes con cada fuente. Se optó por la entrevista abierta y como derrotero común se tuvo mirar el trayecto en la organización, la gestión y el desarrollo de las estrategias comunicativas, la experiencia en el sector público y sus percepciones frente a las situaciones vividas. Se conversó, de igual manera, con quince personas más, directores de las organizaciones, filósofos, comunicadores y sociólogos, con los que se logró profundizar en el contexto de cada proyecto.

Se tuvo siete fuentes documentales como unidades de trabajo, productos de la sistematización y la memoria de los proyectos sociales y de las acciones desarrolladas en el sector gubernamental. Para ambas unidades, se hizo un proceso de análisis mediante el cruce de la triangulación hermenéutica (Cisterna, 2005) y la teoría fundamentada (Strauss y Corbin, 2002). La primera permite hacer un proceso de organización, cruce e interpretación dialéctica de la información recolectada y pertinente al objeto de estudio. Cisterna (2005) sugiere el procedimiento inferencial, que consiste en establecer conclusiones de manera ascendente, organizándolas a partir de tendencias que ayuden a clasificarlas en coincidencias o divergencias. Esto implica que haya diferentes niveles de síntesis de tipo subcategorial, categorial y de opiniones. La segunda obliga al desarrollo de pasos sistemáticos para configurar con más solidez el entretejido categorial, le exige al investigador una mirada microscopia de los datos.

\section{Algunas notas teóricas}

Esta investigación planteó la relación categorial ciudadanía-comunicación-lo público estrechamente vinculadas entre sí. De ellas, y en el contexto del objeto de estudio, emerge la ética como categoría transversal; a ella se suman los conceptos de las emociones y la autoestima social, y en su lectura global se visibilizó la categoría de ciudadanía comunicativa.

Siguiendo a Bárcena (1997), la ciudadanía es un concepto contestable por su complejidad, dinamismo y formación en el tiempo. Si bien su análisis puede remontarse a la Grecia clásica y a la referencia tradicional que se encuentra en Ciudadanía y clase social de Marshall (1997), quien desde una perspectiva histórica analiza el alcance de los derechos civiles, políticos y sociales. La pregunta de la cual partió el estudio de este concepto fue la siguiente: ¿cuáles son 
los rasgos de la ciudadanía que concentró el foco de atención de las organizaciones del tercer sector en Medellín? Para dar respuesta, las claves se encontraron en la noción de ciudadanías mestizas ${ }^{5}$ de Uribe, quien explica la amalgama de las ideas republicanas y liberales con las lógicas de las comunidades locales enraizadas en el territorio. Hace una revisión sistemática, en clave histórico-cultural, de las cartas políticas que han regido al país y las prácticas políticas de las comunidades, que son la expresión de las luchas de los ciudadanos por sus derechos y el reconocimiento social en el ámbito de lo público:

La acción política no se limita al discurso y a la práctica, también entra la fuerza, la sangre, la guerra como estrategias bastantes socorridas para trazar umbrales de inclusión-exclusión y para ampliar o restringir el derecho a la nación y a la ciudad [...]. En Colombia, la guerra tiene palabra, relatos discursos, no solo en el campo de las justificaciones, como lo tienen todas las guerras del mundo, sino que ha logrado desarrollar una retórica eficaz y una diplomacia infinita y armada. (Uribe, 2001, p. 213)

También se consultaron los trabajos hechos por los antropólogos Naranjo, Hurtado y Peralta (2001), que dan cuenta de los trayectos recorridos por la noción de ciudadanía, desplazándose desde contextos políticos hasta escenarios más socioculturales. Se basan en los planteamientos de De Sousa Santos (2012), quien indica que el ciudadano parte del principio de la subjetividad que trasciende lo civil y lo político del concepto de ciudadanía, dado que, en este último, se excluyen otras formas de participación política que están impregnadas de contenido social y cultural.

La categoría pasa a ser menos coactiva atada a una idea de Estado-nación en la que los sujetos gestionan sus conflictos sociales desde la diferencia, la libertad individual, la voluntad colectiva y un sistema político autónomo (Naranjo et al., 2001, p. 53). En este sentido, sostiene que la ciudadanía es un proceso de subjetivación-individuación, las personas se asumen como individuos, intervienen desde su voluntad con pleno derecho:

Cuando el sujeto actúa como ciudadano, ensambla una triple relación que, desde su situación, condición y acción, se inscribe en una dinámica por el reconocimiento social. En efecto, el punto de partida es la situación o las relaciones sociales de desigualdad y asimetría, con las cuales el sujeto, en su condición de igualdad ante la ley, despliega una acción por la ampliación de la dignidad humana y las condiciones de justicia social. Así, en vez de cumplir un rol de ciudadano a la espera de una ciudad justa o una ciudad feliz para todos, hace parte de un sistema de acción social histórico por el

5 Uribe (2001, p. 185) argumenta que su análisis es coherente con las propuestas de García Canclini, quien propone la noción de ciudadanías híbridas, y la de Francois Xavier Guerra, ciudadanías alternativas. 
reconocimiento social, económico, político y cultural. (p. 51)

Naranjo et al. recurren a las categorías de industrias culturales y consumo cultural, desde las discusiones que plantean García Canclini y Martín-Barbero, para comprender el sistema social a partir de la reelaboración simbólica de lo material. Los medios comunitarios en la ciudad se convirtieron en una herramienta de la lucha de la población por su inclusión: rápidamente los asumieron como dispositivo para contar lo que eran y poner en agenda pública lo que les acaecía, fueron mediadores en los procesos colectivos y sirvieron para armonizar el ingreso de los nuevos plebeyos al nuevo sistema social (2001, p. 33).

La noción de ciudadanía y consumo propuesta por García Canclini (1995) nos acerca a un ciudadano más real y cercano a los procesos impulsados por las organizaciones objeto de estudio, personas habitantes de un territorio en disputa por las fuerzas de poder legales e ilegales que inciden en la formación de sus valores, en la perspectiva de vida, la credibilidad de la institucionalidad y de la vecindad, apática a todo aquello que tuviera un tinte político.

Ser ciudadano no tiene que ver solo con los derechos reconocidos por los aparatos estatales a los que nacieron en un territorio, sino también con las prácticas sociales y culturales que dan sentido de pertenencia y hacen sentir diferentes a quienes poseen una misma lengua, semejantes formas de organizarse y satisfacer sus necesidades. (1995, p. 19)
Bajo este marco, la categoría de ciudadanía comunicativa ingresa desde los medios y el derecho a la libre expresión. Mata (2006) desarrolla la tensión del sujeto entre la condición de ser público de los medios y su condición de ciudadanía. Indica que los ciudadanos se hacen visibles en los medios como sujetos de necesidad, sujetos de derechos y sujetos de decisión, mientras que los medios se autorrepresentan como escenarios de deber vinculados a la condición ciudadana y a espacios insustituibles para la vida del común y la producción política, requeridos por la acción de los sujetos que demandan datos, información y nociones que los orienten.

Mata también propone la ciudadanía comunicativa como objeto para garantizar los derechos de los ciudadanos en el campo de la comunicación y, la subdivide en formal (ciudadanos depositarios de los derechos), reconocida (ciudadanos que reconocen dichos derechos como integrantes de una comunidad), ejercida (por los ciudadanos que desarrollan prácticas sociales que amplifican dichos derechos) e ideal (que corresponde a la utopía de la democratización de la sociedad) (2006, pp. 13-14).

En una línea similar, se encuentran las posturas de Tamayo (2012). Para él, la ciudadanía comunicativa es un concepto interdisciplinario preocupado por los valores de igualdad, solidaridad, acceso a la tecnología, respeto a la diferencia, justicia, participación, conocimiento y calidad de vida en el escenario global. El autor reitera la relación directa entre la 
libertad de prensa y la libre expresión, como derechos civiles, y la formación de una esfera pública democrática.

Para Camacho (2004), los estudios culturales posibilitan entender las relaciones de consumo, complicidad, seducción, participación, usos y prácticas entre las personas y los medios. Indica que se puede ejercer ciudadanía a través de los medios y en relación con ellos, es decir, en doble vía: de los medios al ciudadano desde la oferta mediática, o del ciudadano a los medios a partir del consumo cultural.

Pero es Muñoz (2006) quien se demarca de los medios y propone una lectura desde el ámbito cultural, centra la interacción comunicación-cultura y políticas de juventud. Lo acota desde la comprensión del sujeto-joven, con relación al contexto colombiano: complejiza la relación con las esferas de la estética, la ética y la política, apostando por diversas formas de acción en lo público que se encarnen en una "ciudadanía comunicativa” (p. 7). Así, señala lo siguiente:

Estaríamos postulando una nueva ciudadanía, cuya acción en la vida cotidiana se manifiesta en claves que no tienen clara expresión en términos de derechos: 'afectar los cuerpos sociales', tomarse el espacio público ('hacer plantones' y convertir las calles de la ciudad en 'territorios habitados'), 'abrir espacios donde la diversidad sea válida', 'tocar a los otros', 'experimentar, crear, con-mover, amar la vida, vivirla con alegría...'. Estamos en el terreno utópico de la dimensión estética. Las opciones de futuro que sueñan y construyen jóvenes en calidad de 'agentes culturalmente activos' se mueven en la dimensión subterránea del encuentro y de la pasión, de la emoción compartida. (2006, p. 191)

Apelar por una ética pública fue el marco inicial desde el que se concibieron las estrategias de comunicación en la ciudad de Medellín. El confrontar el discurso de la muerte con el de la vida determinó los discursos; por ello, la ética es un concepto que no puede excluirse de una idea de ciudadanía, esta se ejerce tanto en lo individual como en lo colectivo. Lo ético se relaciona con los juicios morales, emociones y comportamientos. Camps (2011) plantea que

en una democracia, el individuo es ciudadano $y$, como tal, es sujeto de derechos, pero también de deberes. Los deberes son los que llamamos virtudes cívicas, que consisten en el conjunto de obligaciones que comprometen con lo público o el interés general, que harán del individuo, en principio interesado por sí mismo y los suyos, una persona dotada de civilidad. (p. 33)

Estas estrategias no pueden estar aisladas de los sentimientos y emociones del ser humano; por ello, es pertinente la propuesta de Camps respecto de vincular a la ética las emociones como dinamizadoras de las acciones de los sujetos ${ }^{6}$. Estas se entienden como

6 La tesis central de las emociones parte de los postulados de Aristóteles en sus textos Ética a Nicómaco y la Retórica, la Ética de Spinoza, y el Tratado sobre la naturaleza humana de Hume. 
disposiciones mentales que producen actitudes (maneras de ser) en el ser humano. Tienen un primer componente cognitivo, que proporciona una idea del mundo que se construye socialmente, y un componente desiderativo, el cual moviliza al sujeto a la acción en pro de su propósito. El ser humano no puede abstraerse de su dimensión afectiva. Unido a ello, propone el concepto de autoestima social referida a la percepción que tienen los sujetos sociales de su propia imagen: para Aristóteles era la magnanimidad; en Spinoza, el contento de sí, y en Hume, el orgullo, todas sensaciones relacionadas con la confianza y el aprecio que el sujeto tiene de sí mismo.

La noción de ciudadanía comunicativa que se configura en la ciudad trasciende a la condición política de los derechos y se acerca más al proceso de subjetivación-individuación de Naranjo et al. (2001). Él considera la autoestima social como una categoría por explorar para comprenderla, puesto que, en lo vivido, otro marco que ha determinado la esencia de los discursos comunicacionales ha sido el territorio, que se construye en lo social y define la identidad de quien lo habita. Interesa esta noción porque da cuenta de cómo opera la percepción de sí en lo colectivo, clave para escudriñar el comportamiento de los sujetos sociales en un momento histórico determinado.

En Medellín, la comunicación se ha vivido de manera procesual, se concibió como diálogo interdisciplinar en los procesos de intervención, la producción mediática tuvo el doble rol de ser cohesionadora a través de la creación y gestión mediática, y fue el espacio para el mestizaje cultural y la reelaboración simbólica de las comunidades.

Estas categorías permitieron construir trayectos vistos desde los actores sociales intervinientes en la investigación (Estado-ONG-comunidades), cada uno mediado por marcos socioestructurales de actuación (lógicas de acción, normas, comportamientos) y sociosimbólicos (emociones, representaciones, valores) y generar significaciones en el ámbito de lo público. La noción de ciudadanía emana del Estado de derecho materializada en estrategias intencionadas y dirigidas hacia la población en diálogo con las entidades de poder, así como en productos mediáticos que permiten la visibilidad y circulación de las luchas por el reconocimiento agenciadas por las comunidades, y vinculadas al territorio como elemento de propiedad, pertenencia e identidad.

\section{Reconfigurando el relato}

Parte de los resultados se organizaron en periodos a partir de los relatos de vida de los comunicadores sociales, lo que permitió esbozar un contexto sobre los hechos sociales que ocurrían en la ciudad y a los cuales respondieron desde la praxis comunicativa. El primer periodo abarcó desde los planteamientos comunicacionales, con el Modelo de Comunicación Macrointencional de Fundación Social en 1989, hasta la implementación del Modelo de Comunicación Pública Organizacional e Informativa 
para las Entidades del Estado (MCPOI) en el 2005. El segundo partió de los procesos que se generaron en Corporación Región desde 1989, fecha en la que fue creada, hasta cuando Salazar cumplió su periodo administrativo en la alcaldía, en el 2010. El último se inició en 1967, con las primeras funciones sobre comunicación que se dieron en la alcaldía, y se extendió hasta que se llevó a cabo la adaptación e implementación del MCPOI en el 2005. Este trayecto se reconstruye con el fin de comprobar el supuesto sobre el saber comunicacional que se instaló en el Estado en la primera década del siglo XXI, el cual provenía del sector social. A continuación, se sintetiza los recorridos.

Hay que empezar reconociendo que Medellín, como cualquier ciudad, es compleja, pues se configura a partir de las tensiones y contradicciones que ella encarna y son su esencia. A nivel mundial, se le conoce por la violencia que generó el narcotráfico $\mathrm{y}$, a la vez, goza de reconocimientos por su capacidad de reinventarse; entre los múltiples premios que ha obtenido se destaca el de la ciudad más innovadora del mundo, título otorgado en el 2013 en el concurso City of the Year, organizado por The Wall Street Journal y Citigroup. Destacaron las estrategias de planeación e inclusión, de intervención para recuperar el tejido social y prácticas de corresponsabilidad social, implementadas en respuesta a los hechos de violencia que se vivía. Exaltaron el sistema integrado del metro como transporte público y la labor de la Empresa Pública de Medellín (EPM), considerada una de las grandes empresas del país. Ofrece los servicios públicos a todas las clases sociales, aspecto que no es menor, dado que genera igualdad de condiciones para toda la población. Es la misma agua, luz, gas tanto para las personas que viven en el estrato uno como para las que están en el seis ${ }^{7}$. Estos logros, sin embargo, no ocultan las contradicciones sociales permanentes que vive la ciudad entre la competitividad y la inequidad social, la reducción de muerte y la permanencia de la violencia, la activa participación ciudadana en la gestión pública y la corrupción, un mayor PIB per cápita y la pobreza, la industria de punta y el desempleo, etcétera.

Entre las investigaciones sobre la ciudad que ha hecho la Corporación Región (Naranjo, 1992; Naranjo y Villa, 1997; Naranjo et al., 2001; Uribe, 2001; Bernal y Álvarez, 2005; Villa, 2007) y que contribuyen en el conocimiento de los rasgos de la ciudadanía que habita la ciudad, una de las relaciones exploradas se da entre la manera como se fue poblando la ciudad y la planificación

7 En Colombia, se establece una estratificación socioeconómica que va desde el uno hasta el seis, de acuerdo con los inmuebles residenciales que reciben servicios públicos domiciliarios. Así establecen el cobro de manera diferencial, los que tienen mayor capacidad de pago subsidian a los estratos bajos. 
de esta por parte de las entidades territoriales. Como en la mayoría de las ciudades capitales del país, los pobladores que llegaron a ocupar terrenos de manera ilegal ejercen presión social para ser incluidos en el área urbana y ser legalizados. Con ello se producen prácticas e interacciones que son la base de la constitución social y cultural de la ciudadanía de manera particular, es decir, por zonas de la misma ciudad.

Medellín se fue poblando a raíz de las migraciones de las personas del campo a la ciudad. Una primera oleada se dio a finales del siglo xIX y principios del $\mathrm{xx}$, los migrantes llegaron como fuerza laboral para el ferrocarril y las nacientes industrias cervecera, de textiles y tabacalera. La segunda oleada se presentó a mitad del siglo xx a causa de la violencia bipartidista entre liberales y conservadores; esta población no se asumió como mano de obra, sino como amenaza, pues llegó a habitar las laderas de la periferia -y con ella, el sincretismo entre las costumbres campesinas y la cultura de la urbe-, eran los otros que desconocían las reglas de urbanidad.

Las carencias de un techo, servicios básicos y acceso a la salud y la educación expresan el recrudecimiento de la pobreza. Se promueven, entonces, políticas nacionales que garanticen la vivienda y se insta a la organización de la misma comunidad: se crea en 1958 las juntas de acción comunal (JAC), organizaciones civiles sin ánimo de lucro conformadas por vecinos que se unen para sumar esfuerzos en pro de solucionar sus necesidades, como fomentar la autoconstrucción de viviendas y la adecuación básica de vías, servicios públicos, salud, educación. Las JAC se convirtieron en los actores válidos para representar a las comunidades en las instancias de poder; con este rol, la importancia del colectivo fue la del núcleo básico del tejido social.

Las JAC estaban (y aún lo están) asociadas a prácticas clientelistas y cacicazgos, dado que, al congregar a la población de los barrios, los políticos vieron la posibilidad de transar votos por favores políticos. Y a su vez, las JAC también fueron vinculadas a ideas comunistas (Naranjo, 1992; Uribe, 2001); varios de sus líderes trabajaban en fábricas donde se dio la confluencia entre los sindicatos que impulsó la iglesia católica y el patronazgo antioqueño, con la organización obrera que adoptaba las premisas del Manifiesto del Partido Comunista de Marx y Engels.

En la vida barrial, incidían entonces las tensiones del contexto nacional e internacional, los movimientos sociales entran en escena: el obrero, el campesino, el estudiantil. La población siguió aumentando y era más limitado el acceso a los servicios básicos; además, había que suplir las necesidades de cualquier forma, de modo que se incentivó la cultura de lo fácil. Entre otros, estos elementos fueron eco de las primeras acciones del narcotráfico: la venta de la marihuana y contrabando en la década del setenta.

La década del ochenta es considerada la década pérdida. Villa (2007) señala que estos años se recuerdan 
como los más cruentos que vivió el país, pues se agudizaron todas las crisis: el desempleo, las protestas barriales por valorización, las movilizaciones estudiantiles en contra del régimen, la represión social, la delincuencia, la poca cobertura de los servicios, el aumento de tugurios y barrios de invasión, los desfases entre las demandas de la población y la respuesta del Estado... Fue "la década pérdida, marcada por el derrumbe de paradigmas, de muros, utopías, y una suerte de vacío social" (p. 111). La población que llegaba a la urbe era desplazada por la violencia entre el ejército y la guerrilla, y el narcotráfico irrumpía con toda la fuerza que halló en las poblaciones más vulnerables para conformar sus grupos delincuenciales. A Pablo Escobar se le conoció como el mesías que llegó a proporcionar a la población los bienes que el Estado y las élites negaban, y los medios de comunicación lo presentaron en esa época como el Robin Hood criollo.

Emergió el sicariato, Escobar ofreció el pago de un millón de pesos por policía muerto, la circulación del dinero mal habido fue la respuesta para que los jóvenes pudieran satisfacer sus necesidades materiales: tener moto, vestido, mujeres y el dinero para "la cucha" (la mamá); se impuso la cultura del narcotráfico, maneras de hacer, pensar y sentir la vida desde el punto de vista del traqueto ${ }^{8}$. Las fronteras se desdibujaron, el narcotráfico penetró la política, el sistema judicial, la escuela, y en las calles, con las armas y el dinero, vinieron otros abusos: estafa, pelea por el territorio, violaciones, etcétera.

El Estado fue incapaz de responder a todo esto y surgieron otros actores armados: las milicias populares, vinculadas a las ideas y acciones de las guerrillas, y los paramilitares, cuyo objetivo era acabar con aquellos que tenían ideas de izquierda. Cada actor imponía sus valores y reglas - que se confundieron-, y todos terminaron imbuidos en la confrontación por la rentabilidad que dejaba las drogas; era una guerra por el mercadeo, las rutas y el territorio. La población civil quedó en el medio y su mayor defensa fue el refugio de su casa, las calles ya no eran el escenario para el encuentro, lo que tuvo mucho impacto en la ciudad. Para la época, las cifras señalaban 381 homicidios por cada 100000 habitantes (Agencia de Cooperación e Inversión de Medellín y el Área Metropolitana, Banco Interamericano de Desarrollo, BID; UN-Hábitat, Alcaldía de Medellín, 2011, p. 16). Salazar (2001) lo describe así en La parábola de Pablo Escobar:

Medellín se convirtió en un territorio de muerte, de guerras entrecruzadas: bandas que enfrentaban bandas, milicias que ejecutaban a delincuentes,

8 Traqueto es la denominación popular que se le da a la persona que trafica con drogas. Con su dinero quiere aparentar la vida de un burgués y hace mezclas de estéticas foráneas y propias. 
grupos de sicarios que asesinaban policías, grupos que exterminaban jóvenes en las esquinas de los barrios pobres [...], todos esos fuegos entrecruzados produjeron ese año (1990) seis mil muertes en la ciudad de Medellín. [...] Territorios vastos sin Dios ni ley y un Estado impotente para controlar la situación. (p. 240)

La Constitución Política de 1991 fue un hito innegable en la historia del país, Colombia pasó de ser consagrada al Corazón de Jesús a un Estado de derecho: la idea de un ciudadano con derechos se posiciona. La carta magna traía herramientas para garantizar la participación y la defensa de la población, figuras como el referéndum, el plebiscito, la revocatoria del mandato y la tutela le dieron otro aire; este fue aprovechado con acierto por las ONG que abanderaron la formación política para promover la participación, una cultura democrática y empoderar a las comunidades en el liderazgo de su propio desarrollo, "acá hubo un fenómeno postconstitucional, en términos de una dinamización de la sociedad civil, que ayudó a crear una conciencia democrática activa" (Alcaldía de Medellín y Banco Interamericano de Desarrollo, 2009, p. 88).

Entre 1990 y 1991, se dieron tres hechos en la ciudad que por su impacto fueron un punto de giro en su comprensión cultural y social. El primero lo protagonizó el periodista Alonso Salazar (1990); publicó su texto No nacimos $p a^{\prime}$ semilla, donde cuenta por primera vez la vida del sicario y se adentra en la cultura de las bandas juveniles. Más que contar la vida de los jóvenes que matan a sueldo, da cuenta del quiebre ético de una sociedad en la que el verbo convivir no se conjugaba. Se trataba de entender las lógicas de estos jóvenes, de leer su racionalidad y moral, sus peculiaridades religiosas - estar rezando a la virgen María Auxiliadora para que pudieran "coronar", cumplir su objetivo-. Era mostrar el desarraigo familiar, las contradicciones de la cultura antioqueña empresarial y colonizadora, el consumo de una clase marginal. Salazar era socio fundador de Corporación Región, una ONG que iniciaba labores en pro del desarrollo, y con esta publicación empieza un diagnóstico de la violencia que la sociedad no podía evadir.

Un segundo hecho fue la proyección de la película Rodrigo D: No futuro de Víctor Gaviria (1991). En ella se contaba la historia de jóvenes del barrio, sicarios, cuya claridad era su desinterés por la vida. El mayor impacto de la película lo produjo la apuesta estética del director, que optó por actores naturales: jóvenes de la comuna que, con su jerga y sus formas de concebir la vida, mostraron al mundo cómo era pertenecer a las laderas de Medellín. Si bien fue un llamado a las élites para que fueran conscientes del problema social, contribuyó a su vez al estigma que se tejió respecto de la población de las llamadas comunas. En la pantalla grande se vio a la Medellín de las casas apiñadas en las montañas, faldas empinadas, terrazas de ladrillo y laberintos, donde el metal, el punk mezclado con el tango y la música de carrilera eran la banda sonora. 
El tercer hecho fue la creación de la Consejería Presidencial para Medellín y su Área Metropolitana durante el gobierno de César Gaviria (1990-1994). Nombraron a la comunicadora María Emma Mejía como directora (1990-1993), y la fortaleza de su gestión fue la estrategia de acercar el Estado al ciudadano desde la acción social y no con las armas: convocó a los sectores sociales, económicos y académicos a pensar la ciudad e imaginar un futuro distinto para ella.

Como estrategia desarrolló procesos de intervención, cooperación internacional, pactos sociales, planeación participativa, y facultó escenarios para la deliberación pública, entre estos, el Seminario Medellín Alternativas de Futuro, del cual se realizaron cinco versiones. Este fue uno de los primeros escalones en la resistencia social contra la violencia, todas las clases sociales convocadas a pensar lo posible. Como lo dijo María Teresa Uribe: “(...) el futuro de la ciudad tendrá que diseñarse con los excluidos, con los pobladores de las comunas pobres, de lo contrario no habrá ciudad, no habrá futuro, no habrá esperanza". (Consejería Presidencial, 1992, p. 18).

También creó el primer programa de comunicación comunitaria en el país que fue emitido por un canal regional, Arriba mi barrio', el cual fue un hito en la ciudad como estrategia masiva de comunicación. El programa visibilizó a los habitantes de los barrios, a los otros jóvenes, que narraron sus logros. El programa se realizaba entre la Consejería, la Universidad de Antioquia y Corporación Región, lo que habilitó el escenario de corresponsabilidad entre el Estado y la sociedad civil ${ }^{10}$. Es decir, las ONG, por su discurso, se negaban a interactuar con el sector público, pero la situación que vivió la ciudad no permitía distinciones, todos tenían que trabajar en ella. Salazar (A. Salazar, comunicación personal, 13 de mayo del 2017) afirma lo siguiente:

La ciudad veía algo que no quería ver. Una de las cosas que aprendí es que la gente no quería hablar de sus problemas sino de sus potencialidades, y nosotros acostumbrados a la denuncia por la denuncia, y la gente no, la gente arreglaba una calle para que se viera el barrio bonito, querían era [sic] que mostráramos la parte bonita de lo que eran sus virtudes. Yo creo que eso desde el punto de vista de comunicación pública es muy importante, aunque nuestra formación de ONG y de izquierda siempre ha buscado como señalar el déficit del problema [...], la Consejería, con esa cantidad de componentes, tuvo la capacidad de poner [a] hablar a muchas personas, de muy distintas procedencias sociales, y a alimentar la capacidad de la sociedad a resistir.

9 El programa comenzó en marzo de 1992 y duró hasta 1997. Hoy en día, el canal Telemedellín produce el programa Camino al barrio (https://telemedellin.tv/programas/camino-al-barrio/), el cual recoge la idea de contar lo que ocurre en los barrios.

10 En sus inicios el programa era presentado por la misma Consejera Presidencial para la ciudad, María Emma Mejía, quien en la actualidad es la embajadora de Colombia ante la OEA, y Alonso Salazar. 
Paralelamente, estaba el trabajo de base y filigrana de las organizaciones comunitarias y las ONG que apostaron por el desarrollo de la ciudad. De las primeras, debe destacarse a Corporación Cultural Nuestra Gente, en el barrio Santa Cruz, zona nororiental. La crearon en 1987, su apuesta fue por el rescate de los jóvenes desde la cultura, darle sentido a la vida desde su capacidad de expresión a través de la danza, el teatro, la música. Era el recobro del cuerpo, de la noche y de la calle, vetada por los grupos al margen de la ley y por el estigma que pesaba sobre los jóvenes que habitaban en la zona. Esta organización fue la primera en mostrar la cultura como vía de intervención.

Junto a ella, está Barrio Comparsa, una propuesta cultural que congregaba a los diferentes grupos de teatro y música de los barrios. Al son del saxo, los platillos y los tambores, personas disfrazadas sobre zancos empezaron a convocar a la comunidad para tomar de nuevo las calles y defender su territorio a través del juego, el teatro o las llamadas lunadas ${ }^{11}$. La música, la pintura, la plástica, la danza se convirtieron en el "arma" para que los jóvenes retornaran a los espacios públicos y las escuelas, así como los medios para crear y fortalecer otras formas de asociación.

El narcotráfico hizo que los organismos internacionales giraran su mirada a la ciudad. Las Naciones Unidas, la alcaldía y Surgir (ONG especialista en el tema) formularon el Plan Municipal para la Prevención de Drogas de Medellín. Para su ejecución, crearon un comité de comunicaciones -coordinado por Liliana Vásquez (L. Vásquez, comunicación personal, 23 de octubre del 2011) - al que se invita a todas las organizaciones sociales que tenían un área de comunicación, para el diseño de la estrategia por aplicar. Como resultado surgieron tres estrategias que marcaron un camino en materia de comunicación en la ciudad: el periódico mural Lado $A$, dirigido a colegios; la idea era que en cada uno se creara el lado B. Luego, el programa radial Donde Céfora ${ }^{12}$, cuya emisión fue por Radioactiva de Caracol y Cristal Estéreo de RCN. En él se hablaba de manera directa sobre drogas y se mezclaban con música, los hits del momento. El programa tuvo el mayor rating de la noche. Las ONG que integraban el comité estaban convencidas

11 Los zancos son palos de maderas utilizados por personas como la extensión de sus piernas y pies. Las lunadas son encuentros que se hacen durante luna llena para leer poemas, entonar canciones y recordar a las personas muertas o desaparecidas.

12 Donde Céfora era un programa de radio en el que se hablaba de drogas y se alternaba con música. Se transmitía por emisoras comerciales, netamente musicales y de gran sintonía, como Caracol radio y RCN. Era la primera vez que productos mediáticos de las ONG tenían un espacio en una emisora comercial, y también era la primera vez que se hablaba del consumo de drogas en un espacio de estos. 
de la importancia de la comunicación para el desarrollo, pero se distanciaban totalmente de gestionar procesos en los medios de bajos recursos. Su apuesta por la incidencia se tenía que hacer con los medios masivos tradicionales, seducirlos a ellos a que se sumaran a su discurso.

Por último, se gestó el Seminario de Periodismo Juvenil, liderado por Corporación Región. Era un evento para el encuentro de las experiencias de comunicación juvenil, tanto escolares como barriales, y la capacitación. Se tornó el referente para toda la ciudad, tanto así que pasó de ser coordinado por Corporación Región a Comfama, que es una caja de compensación ${ }^{13}$, de ahí a las universidades y por último a la administración municipal. Su realización se prolongó durante veinte años y dio cuenta así de todo el espectro de experiencias de comunicación escolar y barrial de toda la ciudad: emisoras, canales comunitarios, periódicos, cómics, altoparlantes dirigidos por líderes comunitarios, clérigos, y colectivos de comunicación.

Como se mencionó, esta investigación se centró en el impacto de dos $\mathrm{ONG}$, entidades concebidas para investigar e intervenir desde la formación política, el desarrollo, la investigación y la deliberación pública: Fundación Social y en Corporación Región.

Fundación Social es una organización que actúa desde la actividad empresarial, los proyectos sociales directos y el macroinflujo. Se focaliza en formar capital social, promover la participación e insertarse en el mercado a través de proyectos sociales directos. Es destacable el trabajo que hicieron en la zona Noroccidental, en cuyo proceso se constituyó la Corporación Picacho con Futuro, y en la comuna 13, donde implementó su modelo Desarrollo Integral Local con un sustento conceptual, político, ético e institucional. En ambas organizaciones se tuvo colectivos de comunicación audiovisual encargados de poner a circular los discursos de los desarrollos de la intervención y hacer noticia de las cotidianidades de su población.

La comunicación de lo público es una de las dimensiones del hacer de Fundación Social, que lo concibe como componente transversal. De esta organización se encuentran grandes legados tanto en lo teórico como en la praxis. Se rescata el Modelo de Comunicación Macrointencional formulado por José Bernardo Toro y las propuestas comunicativas de Juan Camilo Jaramillo, quien propone, desde las experiencias vividas en la puesta en marcha del modelo macrointencional, y acudiendo alllamado de diferentes actores de cooperación internacional y públicos, el Modelo de Comunicación Pública Organizacional e Informativa para las Entidades Públicas (MCPOI). Este modelo fue base para sustentar los estándares de calidad y control del Estado que hoy en día son de obligatorio cumplimiento.

Corporación Región, por su parte, se concibe a sí misma como un centro de pensamiento crítico, una organización de la sociedad civil encauzada en propuestas de participación, democracia, 
equidad e inclusión. Está comprometida con los derechos humanos, las libertades y la vida digna para los sujetos sociales, y convencida de la diversidad cultural, la necesidad de la actuación ética del ciudadano y del mismo entorno. Le apostó a la comunicación masiva con el objetivo de generar opinión pública, ser visible e incidir en los escenarios de poder, una opción totalmente distinta a sus pares. Invitaba a un diálogo social amplio, aún con el Estado, y planteó la comunicación comunitaria para el sector popular (Sierra, 2007).

Un último punto en este relato es la llegada del discurso de las ONG al Estado. Alonso Salazar se retira de Corporación Región y se une a otras personas que veían en la política la vía para generar cambios estructurales en la población. Juntos fundaron Compromiso Ciudadano y lograron llegar a la alcaldía en el 2004 a través del triunfo de Sergio Fajardo (2004-2007). El equipo de gobierno lo conformaron personas procedentes de la academia y las ONG, quienes desarrollaron una propuesta a la que llamaban de buen gobierno. Sus logros y transformaciones son reconocidos en todo el país; de hecho, esta propuesta se prolongó cuatro años más, cuando Salazar ganó la alcaldía (2007-2011).

Los comunicadores que fueron parte de este proceso recogieron los saberes, las estrategias y los modelos que habían aplicado en el sector social; allí todos estaban abocados a posicionar un discurso de cultura democrática y veeduría de lo público. Al llegar al ámbito estatal, tuvieron que involucrarse en los aspectos internos para transmitir, a la cultura organizacional de la entidad territorial, que laborar en el sector público significa generar confianza (USAID, Casals \& Associates Inc., y Comunicación Pública Estrategias, 2004).

Uno de los aportes más visibles y contradictorios fue el darles lugar a las iniciativas comunitarias existentes en la ciudad. Reunieron a los involucrados en la Red de Medios Alternativos para la Convivencia Ciudadana (Redecom), los capacitaron y cualificaron; sin embargo, sus propias rivalidades e inexperiencias llevaron a que la red se acabara. Entre las causas de esta ruptura está el acceso al presupuesto participativo - que los puso en competencia- y la falta de normatividad que hay en el país respecto al profesional del campo, puesto que por la Constitución de 1991 se abolió la tarjeta profesional.

A pesar de ello, se logró hacer visible, ante la alcaldía, la gestión de la comunicación comunitaria y alternativa existente en la ciudad. Esto ayudó a que la Secretaría de Comunicaciones viera a estos grupos como población de incidencia directa con la cual interactuar. En la actualidad, esta interacción se materializa en el proceso de gestación y discusión de la política pública de medios, donde el nivel de empoderamiento de los participantes es acorde con la configuración de la ciudadanía en la ciudad, descrita por Uribe (2001) y Naranjo et al. (2001). La visibilidad de los medios comunitarios obtenida en su momento por Redecom permitió 
legitimar, por un lado, a sus representantes como interlocutores válidos $\mathrm{y}$, por otro, lo pedagógico en la formación de la ciudadanía: las propuestas comunicativas que surgen en los barrios contribuyen a los procesos de ciudadanía en la ciudad.

\section{Algunos legados para la discusión}

Preguntarse por el legado de estas estrategias y los procesos de formación de ciudadanía obliga a considerar las situaciones del contexto y los actores que en el momento abanderaron estas iniciativas. En la actualidad, se tiene un territorio que no está vedado y desde el cual se gestiona su propia planeación, una institucionalidad robustecida y con presencia entre la población vulnerable, y jóvenes con mayores oportunidades. La mayoría de los que trabajan en el ámbito comunitario son profesionales y en su praxis vincularon la academia, el barrio y las instituciones (públicas y privadas). Desde ahí, la interacción que se establece se plantea más en términos desde un saber técnico y experiencial que desde el mero asistencialismo.

Pueden señalarse, entonces, algunos legados:

- La acción comunicativa intencionada. Los medios de comunicación en sí mismos fueron un atractivo para los jóvenes, los seducía la posibilidad de expresión que estos brindaban, contar su visión de vida y el ser vistos; les significaba reconocimiento y validez ante sus familias y la comunidad. Ser interpelados por la comunidad en su necesidad de dar a conocer el acontecer local les otorgó un rol, una función y un sentido para su entorno; mejoró la percepción de sí mismos; les amplió las posibilidades de acción comunicativa consciente e intencionada como forma de trabajo en comunidad, y los condujo, a su vez, a objetivarla, estudiarla desde lo teórico y lo práctico para desarrollar estrategias de intervención que fueran mucho más allá de los derechos de expresión. Un ejemplo de ello es el caso de Pasolini, un colectivo de investigación audiovisual que, en el ejercicio participativo de la realización del producto mediático, implementaron dispositivos de formación en ciudadanía.

- El sentido pedagógico de la acción. La relación comunicación-educación siempre ha sido una constante en las acciones comunicacionales, tanto en las organizaciones multilaterales como en las iniciativas mediáticas de la década del cuarenta (por ejemplo, como lo fue en Sutatenza). Si antes los temas eran sobre la salud, la agricultura y las matemáticas, estos pasaron a ser, por el conflicto, el valor de la vida, la ética y la convivencia. En la actualidad son la memoria, el territorio y su planeación; con ello, la identidad se enraíza más. Los mensajes se construyen en clave de pedagogía, la formación política transversaliza la acción de estas organizaciones; es una constante que permanece, su trasfondo es la participación consciente en el escenario de lo público. Lo que cambia 
son las motivaciones y las temáticas. Ahora, los grandes retos están en entender la mediación del contexto globalizado y las tecnologías (redes sociales y demás) que inciden en el comportamiento de los sujetos, pues la capacidad de asombro cada vez es más limitada, emergen otras formas de relaciones y, quizá, otras maneras de otorgar parámetros éticos desde donde se actúa.

- La organización núcleo del tejido social. Para Fundación Social la construcción de lo público no puede darse si no se actúa desde el colectivo, la importancia de la asociación radica en los lazos de solidaridad y cooperación a través de los cuales los sujetos interactúan con otros, la acción conjunta se sobrentiende. El gran aporte de estas organizaciones es el reconocimiento del Estado y la empresa privada como actores con los cuales debe tenerse diálogo, pues no se construye en solitario. Esto conlleva el aprendizaje de las normas, las herramientas y los procedimientos necesarios, como el presupuesto participativo, la cooperación internacional, la planeación de proyectos, entre otros.

Debe resaltarse el proceso pionero de la Consejería Presidencial en la relación Estado-comunidad a través del Programa Integral del Mejoramiento de Barrios Subnormales en Medellín (Primed) porque entendió la importancia de promover la participación activa de la comunidad en la concertación de las estrategias de desarrollo y sembró giros en la mirada y compren- sión de lo que es el sector público: al Estado hay que verlo como actor a quien se le demanda, se le interpela, vigila y con quien se concerta. Un ejemplo de ello, es la política de medios, un proceso que llevan más de tres años y aún está en proceso.

- La memoria y la autoestima social. Corporación Región desde sus inicios desarrolló procesos de investigación desde la memoria, ahora se ha convertido en un marco desde el cual se construye sentido a los discursos comunicacionales. Esto se debe a los procesos nacionales de negociación que se han hecho con los diferentes actores armados; responde a la estrategia de verdad, justicia, perdón y reparación, la que en Medellín se conectó con las búsquedas e iniciativas de estudiarse como sociedad, provenientes de las organizaciones sociales. La memoria se concibe como categoría de análisis y de intervención, puede vincularse a la autoestima social, apuesta por conocer el pasado para remirarse desde su origen, sus procesos y desarrollo para luego planear el futuro. Y esto pasa por exaltar al sujeto, reconocer sus orgullos y potencialidades, lo que brinda confianza y credibilidad en ellos mismos.

Para cerrar, este estudio deja por discutir la categoría de autoestima social, que entra a dialogar con otras (como lo público, las subjetividades para dar cuenta de los procesos sociales de comunicación que se dan en el ejercicio de la ciudadanía), y con ello resignificar el 
sentido del sujeto político en un escenario histórico determinado. De igual manera, deja algunas ideas para explorar la noción del comunicador de lo público como aquel profesional cuya función está abocada al desarrollo de estrategias para la visibilidad, inclusión y participación de sujetos colectivos.

\section{Referencias}

Agencia de Cooperación e Inversión de Medellín y el Área Metropolitana, Banco Interamericano de Desarrollo, UN-Hábitat, Alcaldía de Medellín. (2011). Laboratorio de Medellín. Catálogo de diez prácticas vivas. Medellín: Mesa Editores.

Alcaldía de Medellín y Banco Interamericano de Desarrollo. (2009). Medellín, transformación de una ciudad. Modelo de Buen Gobierno y Desarrollo Social Integral. Recuperado de http://acimedellin.org/wp-content/uploads/publicaciones/libro-transformacion-de-ciudad.pdf

Aristóteles. (349 a. C./1987). Ética nicomaquea. Bogotá: Universales.

Bárcena F. (1997). El oficio de la ciudadanía: introducción a la educación política. Barcelona: Paidós.

Bernal, J., y Álvarez, L. S. (2005). Democracia y ciudadanías. Balance de derechos y libertades en Medellinn. Medellín: Corporación Región.

Bertaux, D. (1999). El enfoque biográfico. Su validez metodológica, sus potencialidades. Proposiciones, (29). Recuperado de http://www.sitiosur.cl/r.php?id=436

Camps, V. (2011). El gobierno de las emociones. Barcelona: Herder.

Camacho, C. (2004). Democratización de la sociedad: entre el derecho a la información y el ejercicio de la ciudadanía comunicativa. Sala de Prensa. Web para profesionales de la comunicación iberoamericanos, 3(71). Recuperado de http://www. saladeprensa.org/art563.htm

Cisterna, F. (2005). Categorización y triangulación como procesos de validación del conocimiento en investigación cualitativa. Theoria, 14(1), 61-71. Recuperado de http://www.redalyc.org/articulo.oa?id=29900107

Consejería Presidencial para Medellín y su Área Metropolitana. (1992). Seminario alternativas y estrategias de futuro para Medellín y su área metropolitana. Medellín: Lealón.

Corporación Surgir. (2009). Crónica de un compromiso. Surgir 1979-2009. 30 años llenos de razones para seguir aportando a la prevención de drogas. Medellín: Corporación Surgir.

De Sousa Santos, B. (2012). De la mano de Alicia: lo social y lo político en la postmodernidad (2. ${ }^{a}$ ed.). Bogotá: Siglo del Hombre Editores, Facultad de Derecho Universidad de los Andes, Ediciones Uniandes. 
García Canclini, N. (1995). Consumidores y ciudadanos. México: Editorial Grijalbo.

Leyva, S. (2010). El proceso de construcción de estatalidad local (1998-2009): la clave para entender el cambio en Medellín. En M. Hermelin, A. Echeverri y J. Giraldo, (Eds.), Medellín, medio ambiente, urbanismo y sociedad (pp. 271-293). Medellín: Centro de Estudios Urbanos y Ambientales, Escuela de Administración, Finanzas e Instituto Tecnológico.

Mata, M. C. (2006). Comunicación y ciudadanía. Problemas teórico-políticos de su articulación. Fronteiras - Estudos midiáticos, VIII(1), 5-15. Recuperado de revistas. unisinos.br/index.php/fronteiras/article/view/6113/3289

Marshall, T. H. (1997). Ciudadanía y clase social. Revista Española De Investigaciones Sociológicas, (79), 297-344. Recuperado de http://www.reis.cis.es/REIS/PDF/ REIS_079_13.pdf (conferencias A. Marshall, originalmente dictadas en Cambridge, 1949)

Muñoz, G. (2006). La comunicación en los mundos juveniles: hacia una ciudadanía comunicativa [versión electrónica]. Manizales: Centro de Estudios Avanzados en Niñez y Juventud, Universidad de Manizales y la Fundación Centro Internacional de Educación y Desarrollo Humano. Recuperado de http://biblioteca.clacso.edu. ar/Colombia/alianza-cinde-umz/20130225045351/tesismunoz.pdf

Naranjo, G. (1992). Medellín en zonas, monografías. Medellín: Corporación Región.

Naranjo, G, y Villa., M. (1997). Entre luces y sombras. Medellín: espacio y políticas urbanas. Medellín: Corporación Región.

Naranjo, G; Hurtado, D.; y Peralta, J. (2001). Ciudad y ciudadanía. Bajo la lente del conflicto urbano. Medellín: Corporación Región.

Salazar, A. (2001). La parábola de Pablo. Bogotá: Planeta.

Sierra, J. F. (diciembre del 2007). La Corporación Región: un actor social y político reflexivo en una sociedad compleja. Desde la Región, (49), 5-31. Recuperado de http://region.org.co/index.php/publicamos/revista/ediciones-anteriores/ item/120-el-papel-de-las-ong-en-la-sociedad

Strauss, A., y Corbin, J. (2002). Bases de la investigación cualitativa. Técnicas y procedimientos para desarrollar la teoría fundamentada. Medellín: Editorial Universidad de Antioquia, Facultad de Enfermería.

Tamayo, C.A. (2012). Ciudadanía comunicativa, aproximaciones preliminares. Signo y Pensamiento. XXX(60), 106-128. Recuperado de http://revistas.javeriana.edu.co/ index.php/signoypensamiento/article/view/2415

Uribe, M. T. (2001). Nación, ciudadano y soberano. Medellín: Corporación Región. 
Usaid, Casals \& Associates Inc., y Comunicación Pública Estrategias. (2004). Modelo de comunicación pública organizacional e informativo para las entidades del Estado (MCPOI). Bogotá: Autor.

Villa, M. I. (2007). Medellín: de aldea a metrópoli. Una mirada al siglo xx desde el espacio urbano. En R. Mocada (Ed.), Historia de las ciudades e historia de Medellín como ciudad (pp. 98-118). Medellín: Corporación Región. 
